\title{
Dopamine Transporter Gene Variant Affecting Expression in Human Brain is Associated with Bipolar Disorder
}

\author{
Julia K Pinsonneault*,', Dawn D Han', Katherine E Burdick², Maria Kataki ${ }^{3}$, Alessandro Bertolino $^{4}$, \\ Anil K Malhotra', Howard H Gu' and Wolfgang Sadee' \\ 'Department of Pharmacology and Program in Pharmacogenomics, The Ohio State University, Columbus, OH, USA; ${ }^{2}$ Division of Psychiatry \\ Research, The Zucker Hillside Hospital, North Shore-Long Island Jewish Health System and Albert Einstein College of Medicine, New York, NY, \\ USA; ${ }^{3}$ Department of Neurology, College of Medicine, The Ohio State University, Columbus, OH, USA; ${ }^{4}$ Psychiatric Neuroscience Group, \\ Department of Neurological and Psychiatric Sciences, University of Bari, Bari, Italy
}

\begin{abstract}
The gene encoding the dopamine transporter (DAT) has been implicated in CNS disorders, but the responsible polymorphisms remain uncertain. To search for regulatory polymorphisms, we measured allelic DAT mRNA expression in substantia nigra of human autopsy brain tissues, using two marker SNPs (rs6347 in exon 9 and rs27072 in the 3'-UTR). Allelic mRNA expression imbalance (AEI), an indicator of cis-acting regulatory polymorphisms, was observed in all tissues heterozygous for either of the two marker SNPs. SNP scanning of the DAT locus with AEl ratios as the phenotype, followed by in vitro molecular genetics studies, demonstrated that rs 27072 $C>T$ affects mRNA expression and translation. Expression of the minor $T$ allele was dynamically regulated in transfected cell cultures, possibly involving microRNA interactions. Both rs6347 and rs3836790 (intron8 5/6 VNTR) also seemed to affect DAT expression, but not the commonly tested 9/I0 VNTR in the 3'UTR (rs28363170). All four polymorphisms (rs6347, intron8 5/6 VNTR, rs27072 and 3'UTR 9/I0 VNTR) were genotyped in clinical cohorts, representing schizophrenia, bipolar disorder, depression, and controls. Only rs27072 was significantly associated with bipolar disorder $(O R=2.1, p=0.03)$. This result was replicated in a second bipolar/control population $(\mathrm{OR}=1.65, p=0.01$ ), supporting a critical role for DAT regulation in bipolar disorder.

Neuropsychopharmacology (20II) 36, I644-1655; doi:I0.1038/npp.20II.45; published online 27 April 20II
\end{abstract}

Keywords: dopamine transporter; bipolar disorder; allelic expression imbalance; SLC6A3; rs27072

\section{INTRODUCTION}

The dopamine transporter (DAT) has a key role in the regulation of dopaminergic neurotransmission via highaffinity reuptake of dopamine into presynaptic terminals. DAT is a target for stimulant medications used to treat ADHD symptoms, and stimulant drugs of abuse such as cocaine, which inhibit DAT dopamine reuptake and increase dopamine activity in the synapse. Genetic variants in the DAT gene (also known as SLC6A3) have been implicated in ADHD (Feng et al, 2005; Ouellet-Morin et al, 2008), schizophrenia (Saiz et al, 2010), bipolar disorder (Mick et al, 2008), posttraumatic stress disorder (Segman et al, 2002), and cocaine abuse (Guindalini et al, 2006).

\footnotetext{
*Correspondence: Dr JK Pinsonneault, Department of Pharmacology, Ohio State University, 333 West IOth Avenue, Columbus OH 43210 1239, USA, Tel: +614 292 5165, Fax: +614 2927232 E-mail: pinsonneault.2@osu.edu

Received 19 October 2010; revised 19 January 2011; accepted 25 February 2011
}

As DAT lacks frequent polymorphisms that directly affect protein structure, such as non-synonymous SNPs, previous studies have focused on regulatory polymorphisms that affect transcription, mRNA processing, and translation. A repeat $\left(9 / 10\right.$ repeat) polymorphism in the $3^{\prime}$ untranslated region ( $3^{\prime} \mathrm{UTR}$ ) ( $\mathrm{rs} 28313670$ ) of DAT has been studied extensively in association studies, but with inconsistent and even contradictory results (Das and Mukhopadhyay, 2007; Feng et al, 2005; Laucht et al, 2007; Todd et al, 2001). In vitro studies on the effect of the $9 / 10$ repeat on gene expression have also yielded inconsistent results (Fuke et al, 2001; Greenwood and Kelsoe, 2003; Mill et al, 2005; Miller and Madras, 2002; VanNess et al, 2005). Using in vitro expression studies, a 5/6 repeat in intron8 (rs3836790) has been reported to affect DAT mRNA expression, modulated by cocaine and agents that stimulate cellular cAMP and $\mathrm{Ca}^{2+}$ (Guindalini et al, 2006). Moreover, the $5 / 6$ repeat has been associated with cocaine abuse, a finding that has yet to be replicated (Guindalini et al, 2006). Numerous association studies have been conducted with additional DAT polymorphisms (Azzato et al, 2009; Feng et al, 2005; Hamidovic et al, 2010; Huang et al, 2010; Ouellet-Morin et al, 2008; 
Pattarachotanant et al, 2010; Reese et al, 2010; Xu et al, 2010), including rs6347 and rs27072. The minor allele of rs6347 was identified as part of a haplotype found to be protective against obesity (Azzato et al, 2009). Of note, rs27072 has been implicated in ADHD (Feng et al, 2005; Ouellet-Morin et al, 2008), but evidence for a functional role of rs27072 is lacking. Therefore, none of the tested DAT variants are unequivocal risk factors with established function in vivo. Thus the first goal of this study was to determine whether and to what extent regulatory polymorphisms affect DAT mRNA expression in human brain autopsy tissues.

Regulatory polymorphisms can be detected by measuring mRNAs specifically generated from each allele, with use of a marker SNP, located in the transcribed region of the target gene. As mRNA expression is tissue dependent, this approach requires human autopsy tissues from brain regions where the gene is functionally expressed. In a series of previous studies, we have detected unexpectedly frequent allelic expression imbalance (AEI) in several candidate genes (Johnson et al, 2008), which was followed by SNP scanning to identify the responsible regulatory polymorphisms (Wang et al, 2008; Wang et al, 2010; Zhang et al, 2007). Several of these newly discovered variants in pharmacologically important candidate genes, such as ACE, DRD2, CHRNA5, and CYP3A4, have demonstrated relevance in clinical association studies (Johnson et al, 2009; Smith et al, 2010; Wang et al, 2008; Wang et al, 2010; Zhang et al, 2007).

In this study, we determined allelic differences of $D A T$ mRNA levels in autopsy brain tissues, selecting substantia nigra as a physiologically relevant region where DAT mRNA is robustly expressed, and the protein then distributed throughout the brain. Significant AEI was traced to regulatory polymorphisms in the transcribed portion of $D A T$, which then were further characterized by in vitro expression in cell cultures. Candidate DAT variants implicated by these results, including the previously characterized 5/6 repeat (Guindalini et al, 2006) and rs27072, were subsequently evaluated in clinical cohorts representing controls and subjects diagnosed with schizophrenia, bipolar disorder, and to address potential clinical relevance. We detected a significant association of only one SNP rs27072, with bipolar disorder, a finding strengthened by demonstrating rs27072 modulation of DAT expression.

\section{SUBJECTS AND METHODS}

\section{Human Subject Cohorts}

OSU buckeye brain bank. A total of 30 human autopsy brain tissues were obtained from substantia nigra, as well as the polar region of the frontal lobe (Ohio State University Neurodegenerative Disease Brain Tissue Repository (Buckeye Brain Bank). Because of limited availability of human substantia nigra autopsies, we used available autopsy tissues from patients with histologically confirmed Alzheimer's disease (AD), under the assumption that the majority of frequent regulatory SNPs will be present in all populations and are likely to exert at least qualitatively similar effects on gene expression in various pathophysiologies. The AD patients were all Caucasians; the average estimated age at onset of $\mathrm{AD}$ was $69.9 \pm 8.8$ years, and the average age at death was $80.3 \pm 9.0$. An analysis of differences between $\mathrm{AD}$ tissues and those obtained from subjects without previous disease diagnoses will require additional tissues from other repositories.

Stanley Consortium tissue repository. We obtained genomic DNA and RNA extracted from the prefrontal cortex of 105 individuals previously diagnosed with bipolar disorder (35) or schizophrenia (35), and 35 controls. Autopsy liver tissue from an additional 80 individuals was obtained, solely for DNA extraction. These subjects had been diagnosed with bipolar disorder (15), schizophrenia (25), and depression (15), and 25 controls. Additional demographical data available for these samples included age and sex.

University of Bari schizophrenia and control subjects. Peripheral blood DNA from 492 subjects (307 controls, 185 schizophrenia patients) was obtained from Alessandro Bertolino (University of Bari, Italy). The cohort has been described in earlier reports (Bertolino et al, 2004; Bertolino et al, 2007; Bertolino et al, 2009; Bertolino et al 2010; Blasi et al, 2009; Zhang et al, 2007).

The Zucker Hillside Hospital (ZHH) cohort of bipolar subjects and controls. Peripheral blood DNA from 413 Caucasian subjects (247 controls and 166 bipolar patients) was obtained from The $\mathrm{ZHH}$ of the North Shore-Long Island Jewish Health System in Glen Oaks, NY. All subjects were diagnosed with a standardized interview (Structured Clinical Interview for the DSM-IV; SCID), with healthy subjects screened using the non-patient version of the SCID (First et al, 1998). Diagnoses were confirmed in a consensus conference comprised of senior researchers, psychiatrists, residents, fellows, and research staff. Bipolar patients had a mean age of $38.5 \pm 12.0$ years and were significantly younger than the healthy controls who had a mean age of $46.5 \pm 14.7$ years $(t=5.8 ; \mathrm{df}=411 ; p<0.001)$. Groups did not significantly differ with regard to sex distribution (Bipolar: $48.2 \%$ female; Healthy: $57.1 \%$ female; $\chi^{2}=3.2$; $\mathrm{df}=1 ; p=0.09)$.

\section{Sample Preparation}

A detailed description of sample preparation from frozen tissue has been described elsewhere (Pinsonneault et al, 2004).

\section{mRNA Levels Measured with Real-Time PCR}

Real-time PCR was carried out on an ABI 7000 instrument (Applied Biosystems) with the following gene-specific primers:

DAT_rs6347_F 5'-TTCATCATCTACCCGGAAGCC-3'; DAT_rs6347_R 5'-GAAGAAGACCACGGCCCAG-3', Actin F $5^{\prime}$-CCTGGCACCCAGCACAAT-3'; Actin R 5'-GCC GATCCACACGGAGTACT-3'

TH-rs6356 F 5'-GGCTGTGGCCTTTGAGGA-3'; TH-rs6356 R $5^{\prime}$-TTGGTGGCCCTCGGG-3' 


\section{SNaPshot Procedure for Measuring Allelic Ratios}

Measurement of allelic ratios of genomic DNA and mRNA has been described earlier (Pinsonneault et al, 2004). For DAT the following primers were used:

DAT rs6347 F 5'-TTCATCATCTACCCGGAAGCC-3';

DAT rs6347 R 5'-GAAGAAGACCACGGCCCAG-3';

DAT rs6347 PEF 5'-ACGCTCCCTCTGTCCTC-3' (PEF:

primer extension forward)

DAT rs27072 F 5'-AGAACACAGTGCCCCTGGG-3';

DAT rs27072 R $5^{\prime}$-AAAAACGTCTAACTTCATGCTGT

CTG-3';

DAT rs27072 PER 5'-CTGCTCCCTGCTCCC-3' (PEF:

primer extension reverse)

The following primers were used for SNaPshot (Life Technologies, Foster City, CA) for cell culture co-transfection experiments.

DAT rs1042098 F 5'-GCCACTGGCTCAAGGTGTAGA-3';

DAT rs1042098 R 5'-TGGTTTGTTCGTGTCTCTCCC-3';

DAT rs1042098 PEF 5'-ACCCCAGGAAGTCATCC- ${ }^{\prime}$

\section{Genotyping Assays}

Standard methods were used to determine SNP genotypes, including $\mathrm{SNaPshot,}$ sequencing and a modified allelespecific PCR method using SYBR Green with melting curves of the amplified DNA (Papp et al, 2003; Zhang et al, 2007). Repeat polymorphisms were measured as follows: fluorescently labeled primer pairs flanking the repeats were used to amplify the region with PCR. The fluorescently labeled fragments were analyzed on the ABI 3730 capillary electrophoresis instrument (Applied Biosystems). The following primers were used:

DAT $3^{\prime}$ UTR VNTR-R $5^{\prime}$-CTTCCTGGAGGTCACGG TCAA GG-3'

DAT $3^{\prime}$ UTR VNTR F $5^{\prime}$-AACCAGCTCAGGCTACTGCCA CTCAG-3'

DAT In8 VNTR F $5^{\prime}$-GCATGTGGATGTGTTCTTGCA- ${ }^{\prime}$

DAT In8 VNTR R $5^{\prime}$-TCATCCCAGGGACATCTGCTA- ${ }^{\prime}$

\section{Statistical Analysis Including Tests for Association to AEI and Clinical Association Studies}

Genetic data were analyzed with SPSS version 17.0 (SPSS Inc. Chicago, IL and HelixTree (Golden Helix), providing genetic association, haplotype estimation and regression analysis capabilities.

\section{Construction of DAT cDNA variants for in vitro expression}

Insertion of rs6347 into the DAT-coding cDNA. The translated portion of DAT cloned into pCDNA3 (obtained from Howard $\mathrm{Gu}$ ) contained the minor allele $(G)$ of rs6347. The rs6347 A allele was inserted with site-directed mutagenesis using the QuikChange II Site-Directed Mutagenesis Kit (Stratagene) and confirmed by sequencing.

Addition of DAT $3^{\prime} U T R$. Constructs containing the entire DAT 3'UTR (obtained from Sidney VanNess) (VanNess et al, 2005) represented either the main allele with the 10 repeat or the minor allele with the 9 repeat, and all of the minor SNP alleles that were in high linkage disequilibrium
(LD) with the 9 repeat allele (rs1042098, rs11564774, rs6876890, rs3797200, rs1809939, and rs7732456). Two additional point mutations in the 9 repeat construct were removed from the construct using site-directed mutagenesis because they were not found in individual tissues nor subjects (no rs annotation). The entire $3^{\prime}$ UTR was cut out with $B s m B I$ and $X b a I$, and the 10 repeat (main allele) $3^{\prime} \mathrm{UTR}$ cloned into a $B s m B \mathrm{I} / \mathrm{XbaI}$ site in the pCDNA3 DAT-coding region constructs containing the $A$ (major) or $G$ (minor) allele of rs6347. The resulting expression vectors were labeled ' $W T$ ' and 'rs6347', respectively. The nine repeat $3^{\prime}$ UTR was cloned into the minor G rs6347 construct to create ' $r$ s6347-9R', and all resulting clones were sequenced. Together, these constructs reflect the most prevalent human $D A T$ haplotypes.

Insertion of rs $27072 \mathrm{G}>\mathrm{A}$ into the WT DAT allele to yield ' $r s 27072$ '. The minor rs27072 A allele was introduced into the WT DAT construct (10 repeat) with site-directed mutagenesis, using the following primers.

rs27072 mutF $5^{\prime}$-CTGCTCCCTGCTCCCAGCTCTGAGGC TG-3'

rs27072 mutR 5'-CAGCCTCAGAGCTGGGAGCAGGGAGC AG- $3^{\prime}$

As the rs27072 $A$ allele resides almost exclusively on the WT 10 repeat allele, we did not generate additional rare haplotypes.

Luciferase constructs for DAT $3^{\prime} U T R$ reporter assays. To create the luciferase constructs containing the $3^{\prime}$ UTRs with 10 repeat, 9 repeat, or 10 repeat/rs27072 (minor 'A' allele), we removed the $D A T$-coding portion of the full cDNA constructs (WT (10 repeat), rs6347-9R (9 repeat) and rs27072 ( $A$ allele)) by digestion with BsmBI, and treated with mung bean nuclease, purified, digested with HindIII, and gel purified the large fragment. The luciferase plasmid pGL3 was digested with $X b a I$, treated with mung bean nuclease, purified, and digested with HindIII to remove the pGL3 $3^{\prime}$ UTR. The luciferase fragment was inserted into the constructs containing the 10 repeat, the 9 repeat, or rs27072, resulting in 'Luc WT', 'Luc 9R', and 'Luc rs27072'.

\section{Transient Transfection in CHO Cells}

$\mathrm{CHO}$ cells were plated into individual wells $\sim 22 \mathrm{~h}$ before transfection and grown in standard media containing $10 \%$ fetal bovine serum (FBS) and antibiotic. For every $1 \mathrm{ml}$ of transfection, we used $1.6 \mu \mathrm{g}$ of plasmid DNA and $4 \mu \mathrm{l}$ lipofectamine 2000 (Invitrogen). Cells were then incubated in standard media containing $10 \%$ FBS and antibiotic, harvested at varying time points in trizol and stored at $-80^{\circ} \mathrm{C}$. Approximately $1 \mu \mathrm{g}$ of RNA from each well was treated with DNase I, Dpn I and Hind III for $30 \mathrm{~min}$ at $37^{\circ} \mathrm{C}$ to remove plasmid DNA. cDNA was synthesized with Superscript III (Invitrogen) using gene specific primers for the SP6 plasmid sequence (5'-CATTTAGGTGACACTATAG$\left.3^{\prime}\right)$ and CHO beta actin. cDNA was used for real-time PCR and $\mathrm{SNaPshot}$ analysis.

Co-transfection of different cDNA constructs. These experiments were designed to detect allelic mRNA expression difference by measuring allelic mRNA ratios, corrected 
by the cDNA ratios of the plasmid pairs transfected into tissue cultures. As allelic expression was found to vary with expression levels (for rs27072), plasmid transfection dilution curves were run. Unless specified otherwise, two different constructs in various combinations were mixed at equal concentrations and either used at full strength, or diluted twofold in five consecutive steps. RNA was collected in trizol at $24 \mathrm{~h}$ following transfection. Dilution experiments (up to $64 \times$ ) with $1: 1 \mathrm{WT} / \mathrm{rs} 27072$ plasmid ratios, and subsequent qPCR demonstrated that the amplification of both components was linear (no significant deviations from $1: 1$ ratios measured even at the highest dilution).

Luciferase-DAT $3^{\prime} U T R$ reporter experiments. Transfections were carried out in $500 \mu \mathrm{l}$ volumes. Every luciferase construct to be tested was co-transfected with $0.2 \mu \mathrm{g}$ pRLTK (Promega), containing renilla luciferase, as control for transfection efficiency. Luciferase and renilla luciferase activities were measured separately at 5,10 , and $12 \mathrm{~min}$ after the addition of appropriate substrate using a Dual Glo Luciferase Assay System kit (Promega). For the dilution series, each dilution of each construct was tested twice individually, on three separate days for a total of six replicates. The fivefold dilution series started with $0.6 \mu \mathrm{g} /$ well of plasmid DNA. In some experiments, $1: 1$ ratios of $3^{\prime}$ UTR WT/rs27072 plasmids were contransfected as in the preceding paragraph, and allelic mRNA ratios measured at rs27072 with increasing dilutions, to test the role of the $3^{\prime}$ UTR in regulating mRNA levels.

\section{Dopamine Uptake in Cells Transfected with DAT cDNA Constructs}

Human DAT cDNA constructs (see above) in pcDNA3 were transfected into CHO cells (American Type Culture Collection, Rockville, MD), using PolyJet In Vitro DNA Transfection Reagent (SignaGen Laboratories, Ljamsville, MD). Cells were grown in 96-well plates. After $48 \mathrm{~h}$, cells were assayed for dopamine uptake in 96-well plates as described (Han \& $\mathrm{Gu}, 2006)$. Briefly, cells were incubated in the $\mathrm{PBS} / \mathrm{Ca} / \mathrm{Mg}$ buffer (phosphate-buffered saline solution containing $1 \mathrm{mM}$ $\mathrm{MgCl}_{2}, 0.1 \mathrm{mM} \mathrm{CaCl}$, and $50 \mu \mathrm{M}$ L-ascorbic acid) containing $60 \mathrm{nM}\left[{ }^{3} \mathrm{H}\right]$-labeled dopamine for $10 \mathrm{~min}$ at room temperature. Uptake was terminated by two successive washes with $\mathrm{PBS} / \mathrm{Ca} / \mathrm{Mg}$. Amounts of $\left[{ }^{3} \mathrm{H}\right]$-labeled substrates accumulated in the cells were quantitated by liquidscintillation counting. All experiments were conducted in triplicate and repeated with several independent plasmid preparations. The total number of replicates in $\mathrm{CHO}$ cells for each construct at each concentration was as follows: undiluted: $n=96,1: 4: n=48,1: 16: n=60$, and 1:64: $n=60$. Cells transfected with vehicle were used as controls, and radioactivity associated with these cells was considered background.

\section{RESULTS}

\section{Genotyping Analysis, Linkage Disequilibrium, and Haplotypes}

We genotyped 14 polymorphisms in DNA extracted from human autopsied substantia nigra of 30 subjects from the

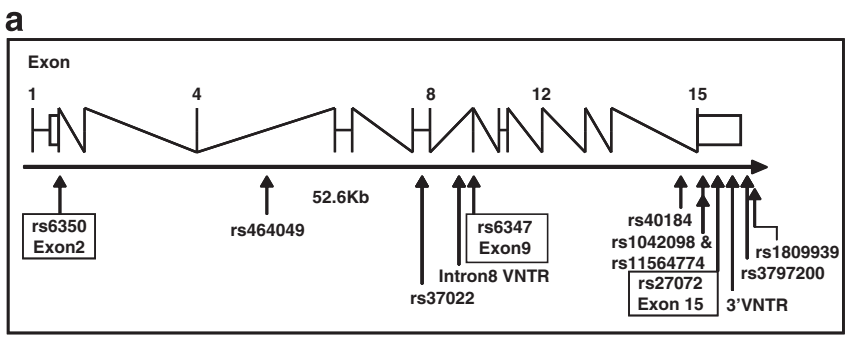

b

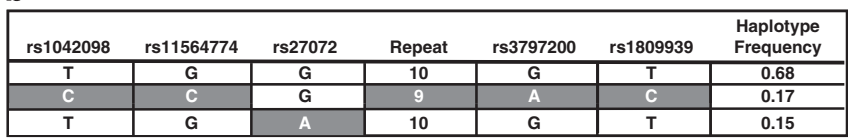

Figure I Dopamine transporter (DAT) gene. (a) Gene structure of DAT showing exon locations and relative positions of the polymorphisms analyzed in this study. (b) Main DAT $3^{\prime}$ untranslated region (UTR) haplotypes, calculated from the substantia nigra tissues. There were no other significant haplotypes. Minor allele is shaded with white text.

Buckeye Brain Bank (Ohio State University) (Supplementary Table S1), including the $9 / 10$ repeat polymorphism rs 28363170 in the $3^{\prime}$ UTR (allele frequency $29 \%$ in the Stanley population) (Figure 1a). Sequencing of the $3^{\prime}$ UTR in all 30 subjects identified four additional frequent SNPs (rs1042098, rs11564774, rs3797200 and rs1809939) in high LD with the $3^{\prime}$ UTR 9/10 VNTR (rs28363170) (all minor alleles residing on the $3^{\prime} \mathrm{UTR} 9$ repeat). One frequent SNP, rs27072 G/A (18\% allele frequency), exclusively resided on the main 10 repeat allele. Another SNP, rs6876890, in high LD with the 9/10 repeat, located in the repeat region, and two additional SNPs heterozygous in only one sample were not analyzed further. The $3^{\prime}$ UTR is encoded by a single exon, yielding three main haplotypes, defined by the $9 / 10$ repeat and rs27072 (Figure 1b). In this study, we have used the 9 and 10 repeat $3^{\prime}$ UTRs, each carrying all SNP alleles in high LD with either the 9 or the 10 repeat, and the 10 repeat variant with the minor 'A' allele of rs27072 - referred to as 9 repeat $3^{\prime} \mathrm{UTR}, 10$ repeat $3^{\prime} \mathrm{UTR}$, and $\mathrm{rs} 2707210$ repeat $3^{\prime}$ UTR. In the brain samples, rs6347 is in LD with the $3^{\prime}$ UTR VNTR (D prime 0.71). The rs6347 minor allele is two times more likely to be found in the same haplotype with the 9 repeat than the 10 repeat (14vs 6\%). LD values for the larger clinical cohorts are presented in Supplementary Table S2.

\section{DAT mRNA Levels in Substantia Nigra Autopsy Tissue}

Levels of DAT mRNA were too low in prefrontal cortex and putamen tissues for accurate quantitation (cycle thresholds $>30$ ). We carried out real-time PCR on cDNA samples prepared from the 30 substantia nigra autopsies, using primers amplifying a region surrounding rs6347 in exon 9 of DAT, with beta actin serving as a house-keeping control gene. Cycle thresholds for DAT ranged from 21-24 for most samples, whereas cycle thresholds for beta actin ranged between 18 and 21.5 (Supplementary Table S3). Four tissues displayed exceedingly low DAT mRNA levels, with PCR cycle thresholds $>30$, suggesting that the tissue sample may not have properly represented the substantia nigra (not further analyzed). After normalizing $D A T$ cycle thresholds to beta actin, delta Ct's were mathematically transformed to arbitrary units representing approximate relative amounts 
of starting DAT mRNA (Supplementary Table S3). None of the DAT polymorphisms was significantly associated with mRNA expression, at least in part because tissue punches were heterogeneous containing varying amounts of dopaminergic cells, resulting in large variation in mRNA levels. To examine this further, we measured the relative expression of tyrosine hydroxylase (TH), another gene expressed primarily in dopaminergic neurons of the substantia nigra. Cycle thresholds for $T H$ were consistently higher, ranging broadly from 26-32 (data not shown), showing a modest correlation with DAT mRNA levels $(\mathrm{R}=0.49)$.

\section{Detection of DAT Allelic mRNA Expression Imbalance in Human Substantia Nigra}

An advantage of the allelic expression imbalance assay is that we can measure cis-acting regulatory effects in any individual heterozygous for a marker SNP. In heterozygous individuals, each allele serves as a control for the other and neutralizes the effect of trans-acting factors that might affect both alleles equally. Allele-specific mRNA expression was measured with two marker SNPs (rs6347 in exon 9 and rs27072 in 3'UTR). These two SNPs are in low LD with each other (D' 0.02, Supplementary Table S2). In all, 14 subjects were heterozygous for either one or the other marker, whereas a single sample was heterozygous for both marker SNPs. In a haplotype analysis of the substantia nigra samples, the rs6347 minor allele is rarely predicted to be on the same haplotype with the minor allele of rs27072, indicating that the two minor alleles reside predominantly on different haplotypes. Allelic ratios of both genomic DNA (gDNA) and mRNA (after conversion to cDNA) were determined using SNaPshot primer extension chemistry. gDNA ratios were normalized to 1.0 ( $\mathrm{SD} \pm 7 \%$ for $\mathrm{rs} 6347$ and $\pm 9 \%$ for rs27072), and allelic mRNA ratios were adjusted accordingly. The gDNA ratios did not significantly deviate from unity in all tissues analyzed, indicating the absence of gene duplications (although deletions are not detectable by this method, because hemizygous and homozygous status cannot be distinguished). Any allelic mRNA ratio that deviates from 1.0 indicates that one allele is expressed more than the other (allelic expression imbalance or AEI). We detected significant AEI ratios in all samples heterozygous for either of the two marker SNPs (rs6347: AEI $=0.71 \pm 0.02$, range $0.58-0.90, \quad p=3.0 \mathrm{E}^{-11}$ different from unity; rs27072: $\mathrm{AEI}=1.38 \pm 0.03$, range $\left.1.10-1.69, p=3.3 \mathrm{E}^{-8}\right)$, indicating the likely presence of cis-acting regulatory polymorphisms (Figure 2, Supplementary Table S1). Unidirectional AEI ratios observed for each marker SNP, either $<1$ or $>1$ in all tissues, implicate both marker SNPs (rs6347 and rs27072) as causative independent of each other, or polymorphisms in substantial LD with either. For rs6347, all allelic mRNA ratios are $<1$ (minor/ major allele), indicating that the minor allele expresses less mRNA than the major allele (the 'wild-type'). In contrast, all allelic ratios measured with $\mathrm{rs} 27072$ are $>1$, with the minor allele expressing more mRNA than the major allele. In the single tissue where both marker SNPs were heterozygous (B129N), significant AEI was observed with both markers, in opposite directions. This result must be considered in the context of the haplotypes carrying the two marker SNPs, with the minor alleles residing on opposite strands. If both

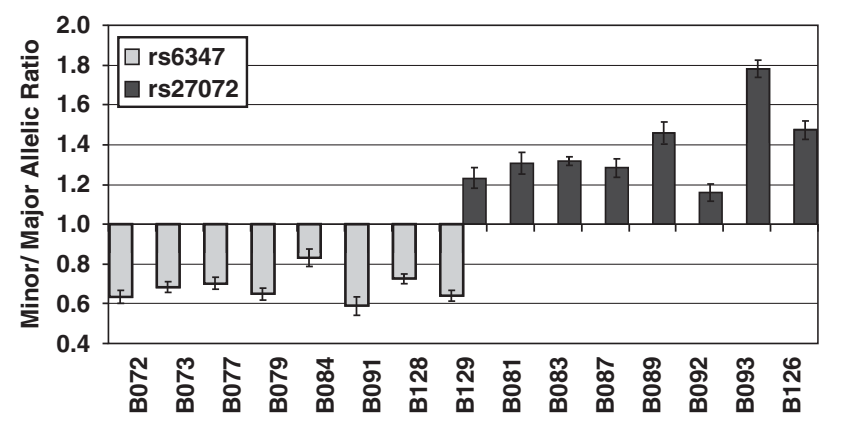

Figure 2 Allelic expression imbalance measured in human substantia nigra autopsy tissue $(n=3)$ using two marker SNPs. All allelic expression imbalance (AEI) ratios were significantly different from I $\left(p=3.3 \times 10^{-09}\right.$ for rs27072 and $p=3.0 \times 10^{-11}$ for rs6347). One tissue was heterozygous for both marker SNPs that reside on different haplotypes, but with opposite effects on the AEl ratio - we expect additive effects, if both SNPS affect allelic expression. However, the AEl ratio of BI29 was similar to those of the other tissues, suggesting that one of the two markers may not be the regulatory variant.

rs6347 and rs27072 were functional and independently additive, we would have expected a significantly greater allelic ratio, for $\mathrm{rs} 6347 \ll 1$ and $\mathrm{rs} 27072 \gg 1$; however, this was not the case. Possibly, either of the two SNPs serves as a surrogate marker for another regulatory variant that is homozygous in this tissue. We therefore scanned the DAT locus for additional polymorphisms that can fully account for the observed AEI ratios.

\section{Mapping AEI to Genotype}

AEI ratios of human substantia nigra samples were compared with the genotypes of 14 polymorphisms. Although the 9/10-repeat in the $3^{\prime} \mathrm{UTR}$, proposed to affect mRNA expression (Inoue-Murayama et al, 2002), has substantial LD with marker SNP rs6347 in exon 9, several samples displaying AEI are homozygous for the 9/10 repeat (Supplementary Table S1). All samples heterozygous for rs27072 displayed AEI, but all were homozygous for the 10 repeat. Therefore, allelic mRNA ratios observed with both markers argue against a regulatory role the 9/10-repeat. Rather, associations between DAT SNPs and AEI are most significant for the two marker SNPs themselves, rs6347 and rs27072 ( $p=0.001$ for both; Figure 3). No other SNP was identified that could have accounted for AEI detected with rs27072, indicating that $\mathrm{rs} 27072$ itself has regulatory functions. However, for AEI detected with marker rs6347, the intron 8 5/6-repeat attained an only slightly lower score (rs3836790; $p=0.007$ ) compared with rs6347 (Figure 3). This small difference is attributable solely to tissue B129N, which is AEI positive, although the intron 8 5/6-repeat is homozygous. Yet, in this single tissue, rs27072 in the $3^{\prime} \mathrm{UTR}$ is also heterozygous, fully accounting for the observed AEI ratio. The intron $85 / 6$-repeat therefore accounts best for the AEI ratios observed with rs6437 as the marker, although we cannot rule out rs6347 as a regulatory polymorphism.

In vitro analysis of rs6437 (exon 9) and rs27072 (3'UTR) in the context of rs28363170 (9/10 repeat VNTR, $3^{\prime}$ UTR)

A previous study had already provided supportive evidence that the 5/6 VNTR (rs3836790, intron8) affects mRNA 


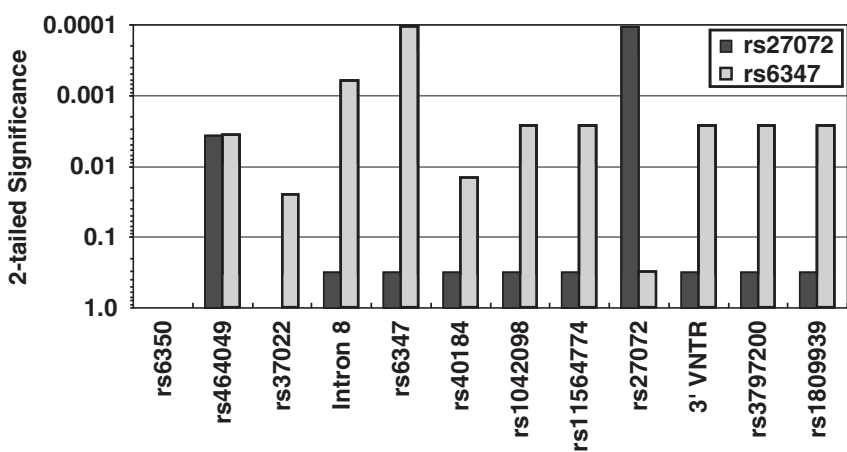

Figure 3 Association of SNPs with allelic mRNA expression in substantia nigra. Alleles of each SNP were sorted according to whether they were found on the high or low expressing allele in the allele-specific mRNA analysis. P-values are two tailed. Tests were conducted for each marker SNP individually (SPSS v. 17 Mann-Whitney test). Note that rs6347 scores better than the intron 8 5/6 repeat, which is homozygous in tissue BI29 where rrs27072 is also heterozygous (Figure 2). If this tissue were to be removed, rs6347 and intron 8 5/6 repeat score identically.

expression, using an in vitro reporter assay (Guindalini et al, 2006). We therefore focused on the exonic rs6347 and rs27072, in haplotypes formed with the 9/10 $3^{\prime}$ UTR repeat. Four human DAT cDNA constructs were made containing naturally occurring combinations: the main haplotype, or wild-type (WT) (rs6347 major allele - 10 repeat - rs27072 major allele), 'rs6347' (rs6347 minor 'G' allele-10 repeat - rs27072 major allele), 'rs6347-9R' (rs6347 minor 'G' allele -9 repeat-rs27072 major allele), and 'rs27072' (rs6347 major allele - 10 repeat - rs27072 minor 'A' allele) (Figure 4). On transfection into $\mathrm{CHO}$ cells, mRNA expression peaked at $\sim 24 \mathrm{~h}$ after transfection and then declined over the next 2-3 days. For a more precise analysis of allelic mRNA expression differences, pairs of cDNA constructs were co-transfected in equal amounts, in the following combinations: 'rs6347' and 'WT' to compare the rs6347 alleles, 'rs6347-9R' and 'rs6347' to compare the 9-repeat with the 10-repeat, and 'rs27072' and 'WT' to compare the alleles of rs27072. Cells were harvested after $24 \mathrm{~h}$, and plasmid DNA ratios and mRNA (after conversion to cDNA) ratios were determined by AEI analysis (Figure 5). Allelic mRNA ratios comparing the 9 and 10 repeats ('rs6347-9R' and ' $r s 6347$ ') yielded rather variable results, with an average ratio of $1.3 \pm 0.2$ over 32 separate transfections, not significantly different from 1.0 (no detectable AEI). This result indicates that, if there is an effect of the $9 / 10$ repeat on expression, it is small. In contrast, the rs 27072 minor ' $A$ ' allele was expressed at a higher level than the main allele ('rs27072' and 'WT'; allelic mRNA ratio $2.0 \pm 0.1$ ), consistent with results in the substantia nigra (Figure 2). On the other hand, the minor ' $G$ ' allele of rs6347 was also expressed at a significantly higher level than the main allele ('rs6347' and 'WT'; allelic mRNA ratio $1.8 \pm 0.1$ ), opposite to the results for substantia nigra where the minor ' $G$ ' allele of rs6347 was associated with lower expression. This result indicates that, if rs6437 has a regulatory function, it is context dependent.

To gain further insight into the dynamics of differential mRNA expression among the alleles tested, allelic mRNA ratios were measured over time after co-transfections of the same allele pairs. When constructs 'rs6347' and 'WT' were

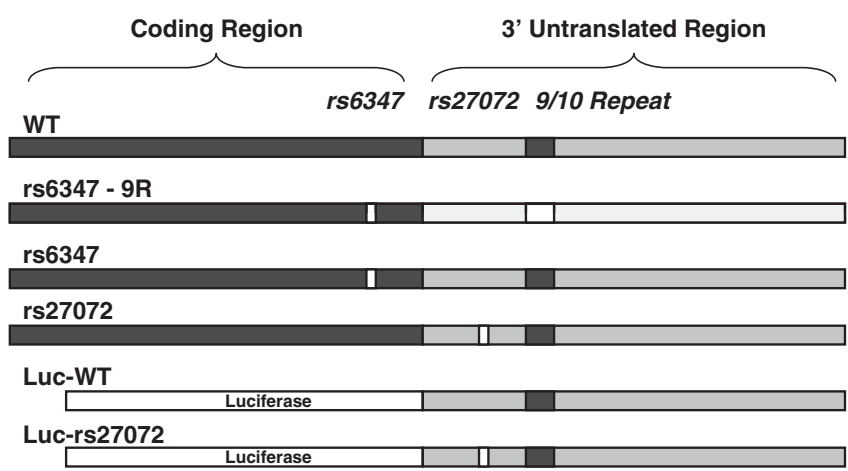

Figure 4 Dopamine transporter (DAT) cDNA constructs tested in cell culture. The construct wild type (WT) contains the major allele of both SNPs rs6347 and rs27072 and the 10 repeat VNTR. The darker gray horizontal bar of the $3^{\prime}$ untranslated region (UTR) represents the reference sequence. The construct rs6347 contains the minor ' $G$ ' allele of rs6347, whereas the construct rs6347-9R contains both the minor ' $G$ ' allele of rs6347 and the 9-repeat variant haplotype, carrying the minor alleles of five other SNPs in the $3^{\prime}$ UTR (represented by a lighter shaded $3^{\prime} \cup T R$ ). The construct rs 27072 containing the minor ' $A$ ' allele of rs 27072 is exclusively associated with the main I0-reapeat haplotype. The lower three constructs contain only the main $3^{\prime} U T R$ variants attached to a luciferase reporter gene.

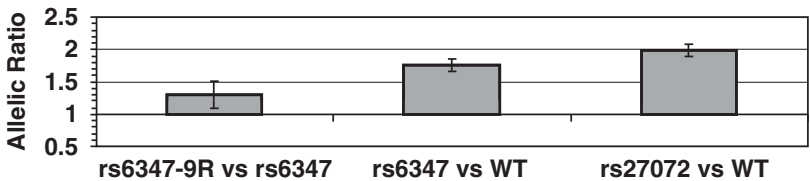

Figure 5 Allelic mRNA ratio measurements of dopamine transporter (DAT) constructs co-expressed in cell culture at $24 \mathrm{~h}$ after transfection. Allelic ratios were calculated as the first listed DAT variant divided by the second variant, normalized to the plasmid cDNA allelic ratios measured for each transfection and time point (set to I). Error bars represent standard error of normalized measurements of ' $n$ ' separate measurements: rs63479 R vs rs6347 ( $n=32,12$ independent transfections, comparing the 9 and 10 repeats in the context of the minor ' $G$ ' allele of rs6347); rs6347 vs wild type (WT) ( $n=35,12$ independent transfections, comparing minor and major alleles of rs6347 in the context of the 10 repeat); rs27072 vs WT ( $n=43,15$ independent transfections, comparing the minor and major allele of rs 27072 in the context of the 10 repeat). At least two different DNA preps were used for each construct (rs6347 and rs27072 in this context refers to the minor alleles.).

co-transfected, allelic mRNA ratios were greatest at $4 \mathrm{~h}$ after transfection, and then declined steadily over the next $72 \mathrm{~h}$ (Supplementary Figure S1). This pattern is consistent with an effect of rs6437 on DAT mRNA formation rate, rather than turnover, in this in vitro cell model.

\section{rs27072 Allele Effects on In Vitro mRNA Expression are Concentration Dependent}

Preliminary results had indicated that $\mathrm{rs} 27072$ effects on DAT mRNA expression vary with plasmid amounts transfected. Therefore, we co-transfected varying amounts of DAT cDNA expression vector pairs ('rs27072' and 'WT') and measured allelic mRNA expression ratios in CHO cells. Allelic ratios were optimally observable at $24 \mathrm{~h}$ after transfection (Supplementary Figure S2). The allelic ratios (minor/major) of rs27072 increased drastically with lower amounts of cDNA vectors applied, up to tenfold (Figure 6a). 


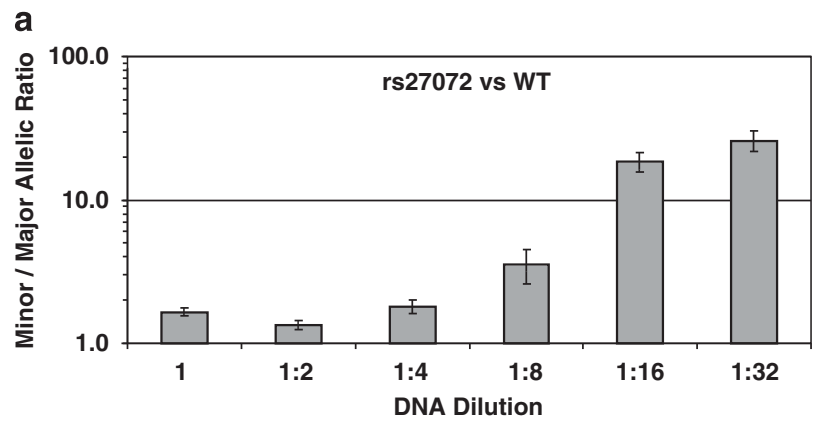

b

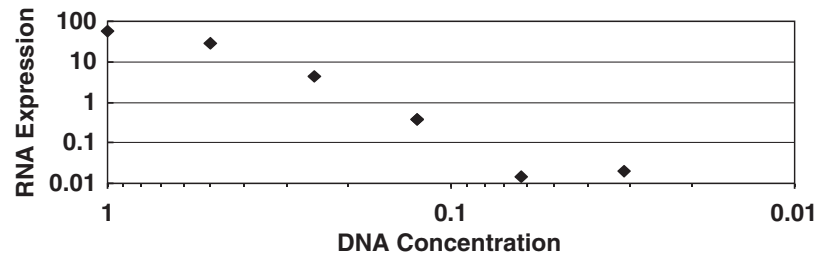

Figure 6 The effect of dopamine transporter (DAT) plasmid DNA concentration on rs27072 allelic mRNA ratios and mRNA expression. (a) Allelic ratios (minor/major) as a function of the amount of plasmid DNA transfected into $\mathrm{CHO}$ cells at $24 \mathrm{~h}$ after transfection. Cells were cotransfected with equal amounts of DAT wild type (WT) and rs 27072 constructs ( $3^{\prime} \cup T R \quad 10$ repeat context), using a twofold serial dilution of both constructs beginning with $0.8 \mu \mathrm{g}$ of each construct. Allelic mRNA ratios were measured at each concentration 6-12 times, and normalized to allelic plasmid DNA ratios set at I.0. (b) A plot of mRNA expression levels (in arbitrary units) for each DNA transfection concentration, as measured by real-time (RT)-PCR.

The overall mRNA levels directly corresponded to the amount of plasmid DNA added to the transfection, except for the lowest plasmid concentration at which measured overall DAT mRNA levels did not further decrease (Figure 6b). As the PCR amplifications seemed to be linear for both rs27072 alleles and the allelic cDNA ratios did not vary with plasmid pair dilutions, the high allelic mRNA ratios reflect a process occurring at the RNA level in the cells. In contrast, no changes in allelic mRNA ratios with increasing dilution of the transfection vectors were detected with the following cDNA pairs: 'rs6347-9R' and 'rs6347' (examining the 9/10 repeat), and 'rs6347' and 'WT' (examining rs6347 effects) (data not shown). The results indicate that allelic DAT mRNA expression strongly depends on transcription levels selectively for the minor 'A' allele of rs27072.

\section{Dopamine Transport Activity of DAT Alleles In Vitro}

To investigate whether rs6437 (exon 9), rs27072 (3'UTR), and rs28363170 (3'UTR 9/10 VNTR) affect functional transporter expression levels, we transfected wild-type $D A T$ (WT) and the same variant alleles used in the preceding experiments and determined dopamine uptake in $\mathrm{CHO}$ cells. To account for variable transfection efficiency between plasmid preparations, three to five clones for each $D A T$ variant were prepared and tested individually. As shown in Figure 7, the rs27072 variant produced slightly less transport activity at the highest transfection concentration ( $8 \%$ reduction, $p=0.03$ ). Generally, DA uptake rates did not differ significantly among the $D A T$ variants tested when

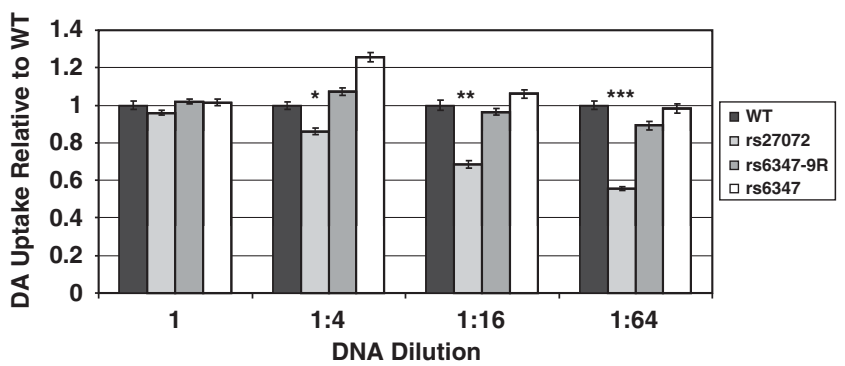

Figure 7 Dopamine uptake by dopamine transporter (DAT) variants at $48 \mathrm{~h}$ after transfection, as a function of plasmid dilution. The fourfold dilution series began with $50 \mathrm{ng} /$ well. The dopamine uptake achieved with the wild-type (WT) plasmid at each dose level was normalized to I (all performed in the same experiment). Note the continuous decline of the expression of the rs 27072 construct relative to $W T$, which is opposite to the relative increase of the mRNA allele shown in Figure 6. Error bars represent SD, $n=48-96$ independent transfections. Significance levels between WT and rs 27072 constructs were determined by T test: * $2.93 \mathrm{E}-$ 06, *** $3.22 \mathrm{E}-14, * * * * 2.56 \mathrm{E}-29$.

50 ng DNA was used for transfections of cells in each well of 96-well plates, even though allelic mRNA expression differed under identical conditions, with the minor allele mRNA being higher compared with the wild type (Figure 6). To test this further, we used decreasing amounts of the variant $D A T$ plasmids in the transfections by diluting the $D A T$ plasmids with empty vector plasmids. Overall transport activity in $\mathrm{CHO}$ declined less steeply as would have been expected, if $D A T$ expression were proportional to the amount of DNA transfected, suggesting that there is saturation of functional protein expression at higher DAT plasmid DNA transfection levels in CHO cells. Yet, neither the rs6437 nor the $9 / 10$ repeat alleles differed consistently from the wild type at each of the dilution steps (Figure 7). In contrast, dopamine uptake activity of DAT variant rs 27072 progressively decreased more steeply than the wild type with increasing dilution, reaching a significant reduction (56\%) when less than $1 \mathrm{ng}$ of DAT plasmid DNA was transfected into the cells. This result contrasts with the finding that at higher dilution, the minor ' $A$ ' allele of rs27072 yielded substantially more mRNA than the major allele (Figure 7). Possibly, the minor rs27072 allele mRNA is sequestered or otherwise not available for translation.

\section{3'UTRs Reporter Gene Assay of Luciferase Expression Activity with Regard to rs27072}

We further investigated $3^{\prime} \mathrm{UTR}$ variants of $D A T$ for their ability to regulate luciferase activity in $\mathrm{CHO}$ cells. DAT $3^{\prime}$ UTRs carrying the rs28363170 10 repeat haplotype, and either the major or minor rs 27072 alleles were subcloned into a luciferase reporter plasmid. The minor $3^{\prime}$ UTR allele of rs27072 consistently yielded a twofold greater luciferase activity than the major allele (Figure 8a). Greater luciferase activity associated with the minor ' $A$ ' allele of $\operatorname{rs} 27072$ is consistent with the higher allelic DAT mRNA expression (Figure 2), but it stands in contrast to the lower DAT transport activity, at least when low amount of $D A T$ vector plasmid was used for transfection (Figure 8). It is likely that cellular processing of the soluble luciferase protein is not saturated so that higher DAT mRNA levels could have 

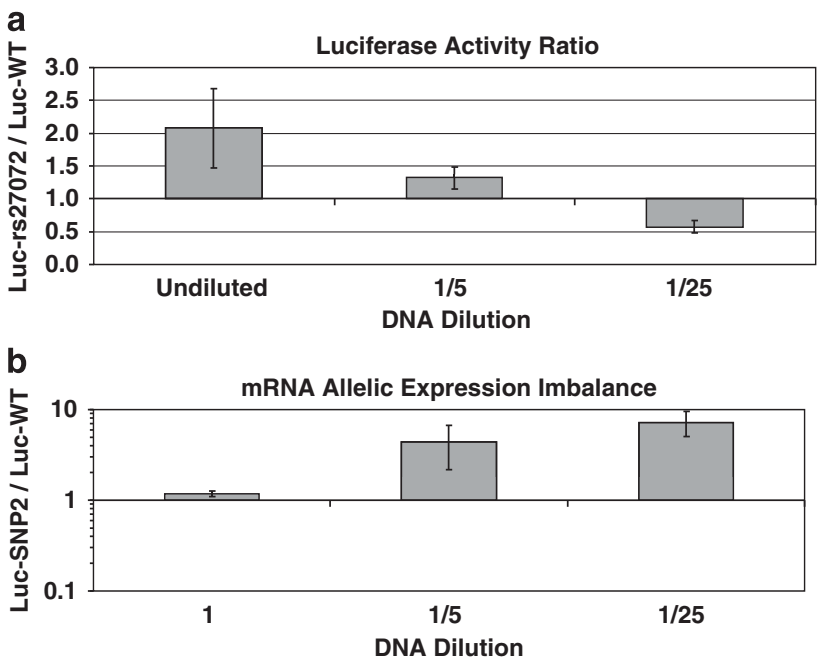

Figure 8 Effect of rs27072 on allelic mRNA expression and relative luciferase activity, as a function of the amount of transfected plasmid, measured at $48 \mathrm{~h}$ after transfection. The Luc-wild-type (WT) 3' untranslated region (UTR) and Luc-rs27072 3'UTR constructs each carry the $3^{\prime} U T R \quad 10$ repeat. For the luciferase activity assay each construct was cotransfected with $0.2 \mu \mathrm{g}$ PRLTK (Promega), expressing renilla luciferase cDNA, serving as a control/reference for transfection efficiency. Luciferase activity was normalized to that of WT. (a) Luc-WT 3'UTR and Lucrs27072 minor allele $3^{\prime}$ UTR were transfected separately, and the luminescence results for rs27072>A (minor allele) were normalized to the activity of rs $27072>G$ (wild-type, major allele) at each dilution. (mean \pm SD, $n=6,3$ independent experiments). The fivefold dilution series started with $0.6 \mu \mathrm{g} /$ well. (b) To measure allelic mRNA ratios, the two constructs were co-transfected in equal amounts as described in Figure 6, and diluted with empty plasmid in a fivefold series. Allelic mRNA ratios were measured with rs27072 as the marker at $24 \mathrm{~h}$ after transfection (mean $\pm S D, n=3$ ).

yielded increased luciferase activity (Figure $8 \mathrm{a}$ ) while not changing DAT transport activity (Figure 7).

To test whether the $3^{\prime}$ UTR carrying the minor 'A' allele of rs27072 is sensitive to the amount of plasmid DNA transfected, even when tethered to the luciferase coding region, luciferase reporter plasmids were transfected at dilutions of $1: 1,1: 5$ dilution, and $1: 25$, and luciferase activities were measured. With increasing dilution of the luciferase plasmids, luminescence activities of the minor rs27072 allele decreased more rapidly, from twofold higher than the major allele at high plasmid concentrations to nearly twofold lower at the $1: 25$ dilution (Figure 8a). This result mimics the effect of significantly lower dopamine transporter activity for rs27072 minor 'A' allele at the highest dilutions (Figure 7).

To test further whether the $3^{\prime}$ UTR with rs27072 follows the same 'sequestration' mechanism regardless of $D A T$ or luciferase as the coding region, we also examined allelic mRNA expression ratios after co-transfection of the luciferase-DAT $3^{\prime} \mathrm{UTR}$ rs27072 alleles at the same three dilution levels (undiluted, 1:5 dilution, and $1: 25$ ). Although at high plasmid doses the allelic mRNA ratios were close to 1 , the minor ' $A$ ' allele mRNA was greatly increased relative to the major allele with increasing dilution (Figure 8b), a similar finding of similar magnitude to what was observed with a $D A T$ wt-rs27072 co-transfection (Figure 6). These results demonstrate that in $\mathrm{CHO}$ cells, the $3^{\prime} \mathrm{UTR}$ mRNA carrying the minor rs27072 allele is protected/sequestered at low levels and thus not available for translations, whereas this mechanism seems to saturate at higher transfection levels.

To address possible saturation events further, we cotransfected low amounts (a $1: 25$ fold dilution, equivalent to $32 \mathrm{ng}$ in $500 \mu \mathrm{l}$ ) of a $1 / 1$ ratio of the major and minor alleles of rs27072 embedded in the full DAT cDNA with increasing amounts of the luciferase-DAT $3^{\prime} \mathrm{UTR}$ s containing either the minor or major allele of rs27072. To distinguish effects of the $3^{\prime}$ UTR reporter constructs on DAT expression, we used the DAT alleles of rs6347 for allelic ratio analysis. We expected that saturation of any mechanism attributable to the minor rs27072 allele with high levels of the $3^{\prime}$ UTR (in the reporter construct) would decrease the allelic ratios measured in the DAT-coding region at rs6347 (this SNP does alter allelic mRNA ratios in vitro but is insensitive to dilution of the transfecting plasmid, determined in separate experiments). Although both $3^{\prime} \mathrm{UTR}$ alleles at high levels affected allelic mRNA ratios, the minor rs27072 allele reduced the allelic ratio 0.7 -fold more $(p=0.01)$ compared with the main rs27072 allele of the $3^{\prime}$ UTR reporter construct (Supplementary Figure S3). This result further supports the notion that the minor rs 27072 allele in the context of the $3^{\prime}$ UTR of DAT triggers a saturable interaction that leads to higher relative mRNA levels, with most of the DAT mRNA inaccessible to translation.

\section{Clinical Association Analyses}

Given the evidence from various molecular genetics results in this study, and guided by previous studies, we have genotyped rs3836790 (intron8 5/6 repeat VNTR), rs6347 (exon 9), rs27072 (3'UTR), and rs28363170 (3'UTR 9/10 repeat) for testing of associations with clinical phenotypes. We also selected three additional polymorphisms because of previous studies suggesting their possible roles in affecting phenotypes: rs464049 (Mick et al, 2008; Talkowski et al, 2008), rs37022 (Preuss et al, 2007), rs40184 (Mick et al, 2008). However, none of these three intronic polymorphisms were implicated by the AEI analysis in substantia nigra. These seven polymorphisms were genotyped in a cohort including subjects with bipolar disorders, schizophrenia, and matched controls obtained from the Stanley Foundation (Table 1). LD measurements between the seven SNPs are shown in Supplementary Table S2. Population characteristics are provided in Supplementary Table S4.

Among the cohorts tested, a significant association between DAT genotype and disease was found only with bipolar disorder (in a sample of 50 bipolar subjects and 60 controls). The minor ' $A$ ' allele of SNP rs27072 was more frequently found in bipolar subjects than controls (allele frequency $24.4 v s 13.3 \%$, respectively; $p=0.03$, OR 2.11 ) (Table 1 ). The intron $85 / 6$ repeat was similarly associated with bipolar disorder in this clinical sample (minor allele frequency $31.5 v s$ 19.5\%, respectively; $p=0.05$, OR 1.90 ). None of the other polymorphisms, including rs6347 and the $3^{\prime}$ UTR 9/10 repeat, were significant. Furthermore, none of the polymorphisms tested was significantly associated with schizophrenia in 60 subjects and 60 controls, obtained from the Stanley Foundation. A further association analysis of four DAT polymorphisms (rs3836790, rs6347, rs27072, and rs28363270) in an Italian population of 185 schizophrenia subjects and 307 controls was also negative (Table 1), 
Table I Results of Basic Allele Genetic Tests Conducted in Control Subjects and Compared with Bipolar or Schizophrenic Populations

\begin{tabular}{|c|c|c|c|c|c|c|c|c|c|c|c|}
\hline \multirow{2}{*}{ Marker } & \multicolumn{7}{|c|}{ Bipolar disorder (Stanley) } & \multicolumn{3}{|c|}{ Schizophrenia (Stanley) } & \multirow{2}{*}{$\begin{array}{c}\begin{array}{c}\text { Schizophrenia } \\
\text { (U. of Bari) }\end{array} \\
\chi^{2} \mathrm{P}\end{array}$} \\
\hline & $\begin{array}{c}\text { MAF } \\
\text { controls }\end{array}$ & $\begin{array}{l}\text { MAF } \\
\text { cases }\end{array}$ & $\begin{array}{c}\text { HWE } \\
\text { P }\end{array}$ & $\chi^{2} \mathbf{P}$ & $\begin{array}{l}\text { Fisher's } \\
\text { exact } \mathbf{P}\end{array}$ & $\begin{array}{l}\text { Odds } \\
\text { ratio }\end{array}$ & $\begin{array}{c}\text { Conf. } \\
\text { interval }\end{array}$ & $\chi^{2} \mathbf{P}$ & $\begin{array}{l}\text { Fisher's } \\
\text { exact } P\end{array}$ & $\begin{array}{l}\text { Odds } \\
\text { ratio }\end{array}$ & \\
\hline rs464049 & 0.33 & 0.38 & 0.30 & 0.45 & 0.54 & 1.26 & $0.7-2.3$ & 0.88 & 1 & 0.96 & ND \\
\hline rs37022 & 0.16 & 0.18 & 1.00 & 0.75 & 0.85 & 1.13 & $0.5-2.3$ & 0.81 & 0.86 & 0.91 & ND \\
\hline rs 40184 & 0.49 & 0.42 & 0.60 & 0.22 & 0.27 & 0.71 & $0.4-1.2$ & 0.61 & 0.64 & 1.17 & ND \\
\hline rs27072 & 0.13 & 0.24 & 0.43 & 0.03 & 0.04 & 2.19 & $1.0-4.3$ & 0.91 & । & 1.05 & 0.69 \\
\hline rs $28363170^{b}$ & 0.28 & 0.31 & 0.42 & 0.73 & 0.76 & 1.11 & $0.6-2.0$ & 0.29 & 0.36 & 0.72 & 0.67 \\
\hline
\end{tabular}

Abbreviation: ND, not determine.

Intron 8 5/6 repeat.

${ }^{b} 3^{\prime} U T R$ 9/10 repeat.

Table 2 Results of a Basic Allele Genetic Test Conducted in the Bipolar Disorder Cohort from the Zucker Hillside Hospital, NY

\begin{tabular}{lccccccc}
\hline $\begin{array}{l}\text { Caucasian } \\
\text { subjects }\end{array}$ & $\chi^{\mathbf{2}} \mathbf{P}$ & $\begin{array}{c}\text { Fisher's } \\
\text { exact } \mathbf{P}\end{array}$ & $\begin{array}{c}\text { Odds } \\
\text { ratio }\end{array}$ & $\begin{array}{c}\text { Confidence } \\
\text { interval }\end{array}$ & $\begin{array}{c}\text { Minor } \\
\text { allele freq. }\end{array}$ & $\begin{array}{c}\text { Case } \mathbf{n}=166 \\
\text { MAF }\end{array}$ & $\begin{array}{c}\text { Control } \mathbf{n}=247 \\
\text { MAF }\end{array}$ \\
\hline Intron 8 & 0.11 & 0.12 & 0.77 & $0.56-1.06$ & 0.26 & 0.24 & 0.29 \\
rs27072 & 0.01 & 0.01 & 1.65 & $1.12-2.41$ & 0.15 & 0.19 & 0.13 \\
\hline
\end{tabular}

suggesting selective effects of the intron 8 5/6 repeat and/or rs27072 on bipolar disorder. Although supported by functional results, these results must be considered in the context of the small sample sizes.

In a replication study, we genotyped the rs27072 and Intron 8 polymorphisms in 166 bipolar patients and 247 healthy controls, all Caucasian subjects from the Zucker Hillside Hospital cohort. The rs27072 minor allele was again significantly associated with bipolar disorder (allele frequency 19 s $13 \%$, respectively; $p=0.01$, OR 1.65) (Table 2). A significant association with the intron $8 \mathrm{SNP}$ was not detected in this cohort.

\section{DISCUSSION}

The dopamine transporter has an important role in dopamine signaling and has been implicated in many disorders of the central nervous system. We have searched for regulatory polymorphisms by measuring DAT mRNAs specifically generated from each allele in substantia nigra human autopsy tissues. Our results support the presence of at least two frequent regulatory polymorphisms, namely rs27072 $C>T$ and the intron $85 / 6$ repeat, although we cannot rule out a function for rs6347. On the other hand, no evidence was found supporting a regulatory function for the $3^{\prime}$ UTR 9/10 repeat frequently used in clinical association studies. The minor $T$ allele of rs27072 was significantly associated with bipolar disorder in two separate cohorts (odds ratio 1.65-2.11), whereas no association was observed with schizophrenia in two populations.

\section{AEI And Genotype in Human Brain}

Significant allelic mRNA expression imbalance (AEI) of $D A T$ in the substantia nigra region of human brain was associated with polymorphisms in the transcribed region of the gene. Examination of the association between AEI and of $14 D A T$ polymorphisms supports the finding that both rs27072 (in the $3^{\prime} \mathrm{UTR}, \sim 15 \%$ allele frequency) and rs3836790 (intron $85 / 6$ repeat, $\sim 26 \%$ allele frequency) are independent regulatory polymorphisms. The allelic mRNA ratios could have also been affected by exon 9 rs6347, with results in only one tissue favoring rs3836790 over rs6347, although a poor correlation argues against a role for rs28363170 (3'UTR 9/10 repeat) in mRNA expression. However, both cannot be ruled out in having a role in this or other tissues. The functionality of the intron $85 / 6$ repeat is further supported by previous in vitro studies of $D A T$ expression by other groups using a reporter gene approach (Brookes et al, 2007; Franke et al, 2008; Franke et al, 2010; Guindalini et al, 2006; Hill et al, 2010). Guindolini et al found that the 5 and 6 repeats (their 'allele 2 ' and 'allele 3') contain some sequence variation within the repeats, but that the 5 repeat expresses less well in a reporter gene-assay testing intronic sequences. However, upon treatments of the cells with agents that increase intracellular $\mathrm{Ca}^{2+}$ and cAMP, expression of the 6 repeat was significantly more stimulated than that of the 5 repeat. This latter observation is consistent with the lower allelic expression of the 5 repeat in the substantia nigra autopsy tissues observed here. We conclude that the minor allele of the intron $85 / 6$ repeat represents a loss of function, at least 
under the conditions relevant to the autopsy tissues. We note that our results were obtained with brain tissues from Alzheimer's patients: possibly, different genotype effects could occur in normal human brain. Nevertheless, the observation of significant effect on DAT mRNA expression, regardless of disease status, supports regulatory functions for the intron 8 5/6-repeat.

\section{In Vitro Characterization of rs27072, rs6347, and the 3'UTR 9/10 Repeat}

The transfection of cDNA constructs in heterologous tissues can yield valuable additional insight into the regulatory mechanisms that may be operative in vivo. As the intron 8 $5 / 6$ repeat had already been tested in vitro (Guindalini et al, 2006), we focused on three additional polymorphisms frequently tested in clinical studies, or implicated by our in vivo AEI results. The minor ' $G$ ' allele of the exon 9 SNP rs6347 yielded lower allelic mRNA levels in transfected CHO cells, but this effect was opposite to that observed in the substantia nigra. At present, we cannot exclude the possibility that rs6347 is active in vivo, possibly in tissues other than the substantia nigra. On the other hand, the effect of the 3'UTR 9/10 repeat on in vitro allelic expression was not statistically significant, paralleling the lack of any effect on allelic mRNA expression in vivo. Similarly, our finding that DAT cDNA constructs carrying rs6347, and the $9 / 10$ repeat failed to produce any differences in DA transport in $\mathrm{CHO}$ cells argues against any significant regulatory function for the $3^{\prime}$ UTR $9 / 10$ repeat. Previous studies have yielded varying results for in vitro effects of the 3'UTR 9/10 repeat (Fuke et al, 2001; Mill et al, 2005; Miller and Madras, 2002; VanNess et al, 2005); taken together we were unable to obtain evidence supporting a regulatory role.

The results of this study for the first time provide strong evidence that rs27072 is associated with both mRNA expression and transporter activity - the minor ' $A$ ' allele yielding higher mRNA levels both in vivo and in vitro. Although this result suggests a gain of function, in vitro dopamine transport assays indicated that the minor allele supports less transport activity than the major allele - a loss of function, particularly at low plasmid DNA concentrations used for transfection. Indeed, at low expression plasmid levels, the minor ' $A$ ' allele of rs27072 reaches more than 10fold higher mRNA expression relative to the major $G$ allele, even though less functional DAT is produced. The same concentration-dependent effect was found with a luciferase expression plasmid carrying the DAT $3^{\prime}$ UTR rs27072 alleles, which are embedded in the main DAT $3^{\prime}$ UTR represented by the 10 repeat VNTR. We propose the hypothesis that the minor allele rs27072 mRNA is sequestered by a yet unknown mechanism, rendering it inaccessible to translation, thereby reducing transport activity. At higher mRNA concentrations, the sequestration mechanism is saturated, so that little or no allelic differences in dopamine transport activity are observed. If this mechanism were also operative in vivo, rs27072 could be classified as a loss-of-function variant, the effect of which is modulated by the transcriptional activity in the target tissue.

mRNA sequestration limiting access to translation in polysomes can occur through the functions of micro RNAs. An in silico analysis of the DAT $3^{\prime}$ UTR sequence for
microRNA target-site prediction using the program RegRNA (Huang et al, 2006) identified multiple micro RNAs with target sites that span the rs27072 SNP locus. We identified five miR's: miR-762, miR-4259, miR-3192, miR3127, and miR-1266 that are promising candidates for further study. For all five micro RNAs, the SNP is within the seed site and, as calculated by the program RNAhybrid (Rehmsmeier et al, 2004), improves miR binding (Supplementary Table S5). This is consistent with functional effects of SNP rs27072 in this study, and with the hypothesis that the minor allele may be sequestered and hence not available for translation. The molecular mechanism underlying these intriguing observations remains to be resolved, and in particular must be studied under conditions that represent the tissue context of the substantia nigra, but it may have bearing on clinical phenotypes, such as bipolar disorder.

\section{Association of DAT Variants With Bipolar Disorder}

We examined four DAT polymorphisms (Intron 8 repeat, rs6347, rs27072, and the $9 / 10$ repeat) in clinical cohorts representing subjects diagnosed with schizophrenia and bipolar disorder. Although no associations were observed with schizophrenia, a significant association of both the rs27072 minor 'A' allele and the intron 85 repeat variant was observed with bipolar disorder in the small cohort from the Stanley Brain Collection, both alleles representing risk factors with odds ratios of $\sim 2$. None of the other variants genotyped in the bipolar cohort was significant. As an odds ratio of 2 is a substantial risk factor with potential clinical relevance, we tested rs27072 and the intron 8 5/6 repeat in a second larger cohort from the Zucker Hillside Hospital. In this cohort of bipolar disorder subjects and controls, only rs27072 scored significantly $(p=0.01$.) with an odds ratio of 1.65 (intron8 5/6 repeat; $p=0.12$ ).

These results support a finding of a true association of rs27072 with bipolar disorder. Taken together with the in vitro data, one could speculate that the sensitivity of the rs27072 minor allele to the expression level of DAT mRNA has a role in the up and down phases of bipolar disorder. If correct, rs27072 DAT could represent a modifier that contributes to diagnosis of bipolar disorder, rather than being a disease risk factor per se. In an ADHD study, the minor 'A' allele of rs27072 was found to be protective (Ouellet-Morin et al, 2008). Perhaps reduced DAT function helps to prevent the occurrence of ADHD, not unlike stimulant medications, used to treat ADHD symptoms by lowering DAT function. The results presented here further suggests a subgroup of bipolar and possibly ADHD subjects, who could respond differently to drug therapy.

\section{ACKNOWLEDGEMENTS}

We wish to acknowledge Dr Doug Scharre head of the Buckeye Brain bank at the Ohio State University. This study was supported by NIH grants from the National Institutes on Drug Abuse (DA022199 and DA014610) and General Medical Sciences (GM092655). 


\section{DISCLOSURE}

The authors declare no conflict of interest.

\section{REFERENCES}

Azzato EM, Morton LM, Bergen AW, Wang SS, Chatterjee N, Kvale $\mathrm{P}$ et al (2009). SLC6A3 and body mass index in the prostate, lung, colorectal and ovarian cancer screening trial. BMC Med Genet 10: 9.

Bertolino A, Caforio G, Blasi G, De Candia M, Latorre V, Petruzzella V et al (2004). Interaction of COMT (Val(108/ 158)Met) genotype and olanzapine treatment on prefrontal cortical function in patients with schizophrenia. Am J Psychiatry 161: 1798-1805.

Bertolino A, Caforio G, Blasi G, Rampino A, Nardini M, Weinberger DR et al (2007). COMT Val158Met polymorphism predicts negative symptoms response to treatment with olanzapine in schizophrenia. Schizophr Res 95: 253-255.

Bertolino A, Fazio L, Di Giorgio A, Blasi G, Romano R, Taurisano P et al (2009). Genetically determined interaction between the dopamine transporter and the D2 receptor on prefronto-striatal activity and volume in humans. J Neurosci 29: 1224-1234.

Bertolino A, Taurisano P, Pisciotta NM, Blasi G, Fazio L, Romano $\mathrm{R}$ et al (2010). Genetically determined measures of striatal D2 signaling predict prefrontal activity during working memory performance. PLoS One 5: e9348.

Blasi G, Lo Bianco L, Taurisano P, Gelao B, Romano R, Fazio L et al (2009). Functional variation of the dopamine D2 receptor gene is associated with emotional control as well as brain activity and connectivity during emotion processing in humans. J Neurosci 29: 14812-14819.

Brookes KJ, Neale BM, Sugden K, Khan N, Asherson P, D'Souza UM (2007). Relationship between VNTR polymorphisms of the human dopamine transporter gene and expression in postmortem midbrain tissue. Am J Med Genet B Neuropsychiatr Genet 144B: 1070-1078.

Das M, Mukhopadhyay K (2007). DAT1 3'-UTR 9R allele: preferential transmission in Indian children with attention deficit hyperactivity disorder. Am J Med Genet B Neuropsychiatr Genet 144B: 826-829.

Feng Y, Wigg KG, Makkar R, Ickowicz A, Pathare T, Tannock R et al (2005). Sequence variation in the $3^{\prime}$-untranslated region of the dopamine transporter gene and attention-deficit hyperactivity disorder (ADHD). Am J Med Genet B Neuropsychiatr Genet 139B: $1-6$

First M, Spitzer R, Williams J, Gibbon M (1998). Structured Clinical Interview for Axis I DSM IV Disorders, Patient Edition (SCIDI/P, Version2.0) edn. Biometric Research Department: New York.

Franke B, Hoogman M, Arias Vasquez A, Heister JG, Savelkoul PJ, Naber $\mathrm{M}$ et al (2008). Association of the dopamine transporter (SLC6A3/DAT1) gene 9-6 haplotype with adult ADHD. Am J Med Genet B Neuropsychiatr Genet 147B: 1576-1579.

Franke B, Vasquez AA, Johansson S, Hoogman M, Romanos J, Boreatti-Hummer A et al (2010). Multicenter analysis of the SLC6A3/DAT1 VNTR haplotype in persistent ADHD suggests differential involvement of the gene in childhood and persistent ADHD. Neuropsychopharmacology 35: 656-664.

Fuke S, Suo S, Takahashi N, Koike H, Sasagawa N, Ishiura S (2001). The VNTR polymorphism of the human dopamine transporter (DAT1) gene affects gene expression. Pharmacogenomics $J$ 1: $152-156$.

Greenwood TA, Kelsoe JR (2003). Promoter and intronic variants affect the transcriptional regulation of the human dopamine transporter gene. Genomics 82: 511-520.

Guindalini C, Howard M, Haddley K, Laranjeira R, Collier D, Ammar $\mathrm{N}$ et al (2006). A dopamine transporter gene functional variant associated with cocaine abuse in a Brazilian sample. Proc Natl Acad Sci USA 103: 4552-4557.

Hamidovic A, Dlugos A, Palmer AA, de Wit H (2010). Polymorphisms in dopamine transporter (SLC6A3) are associated with stimulant effects of D-amphetamine: an exploratory pharmacogenetic study using healthy volunteers. Behav Genet 40: $255-261$.

Hill M, Anney RJ, Gill M, Hawi Z (2010). Functional analysis of intron 8 and $3^{\prime}$ UTR variable number of tandem repeats of SLC6A3: differential activity of intron 8 variants. Pharmacogenomics J 10: 442-447.

Huang HY, Chien CH, Jen KH, Huang HD (2006). RegRNA: an integrated web server for identifying regulatory RNA motifs and elements. Nucleic Acids Res 34: W429-W434.

Huang SY, Chen HK, Ma KH, Shy MJ, Chen JH, Lin WC et al (2010). Association of promoter variants of human dopamine transporter gene with schizophrenia in Han Chinese. Schizophr Res 116: 68-74.

Inoue-Murayama $\mathrm{M}$, Adachi S, Mishima $\mathrm{N}$, Mitani $\mathrm{H}$, Takenaka $\mathrm{O}$, Terao K et al (2002). Variation of variable number of tandem repeat sequences in the $3^{\prime}$-untranslated region of primate dopamine transporter genes that affects reporter gene expression. Neurosci Lett 334: 206-210.

Johnson A, Gong Y, Wang D, Langaee T, Shin J, Cooper-Dehoff R et al (2009). Promoter polymorphisms in ACE (Agiotension I converting enzyme) associated with clinical outcomes in hypertension. Clin Pharmacol Thera 85: 36-44.

Johnson A, Zhang Y, Papp A, Pinsonneault J, Lim J, Saffen D et al (2008). Polymorphisms affecting gene transcription and mRNA processing in pharmacogenetic candidate genes: detection through allelic expression imbalance in human target tissues. Pharmacogenet Genomics 18: 781-791.

Laucht M, Skowronek MH, Becker K, Schmidt MH, Esser G, Schulze TG et al (2007). Interacting effects of the dopamine transporter gene and psychosocial adversity on attentiondeficit/hyperactivity disorder symptoms among 15-year-olds from a high-risk community sample. Arch Gen Psychiatry 64: 585-590.

Mick E, Kim JW, Biederman J, Wozniak J, Wilens T, Spencer T et al (2008). Family based association study of pediatric bipolar disorder and the dopamine transporter gene (SLC6A3). Am J Med Genet B Neuropsychiatr Genet 147B: 1182-1185.

Mill J, Asherson P, Craig I, D’Souza UM (2005). Transient expression analysis of allelic variants of a VNTR in the dopamine transporter gene (DAT1). BMC Genet 6: 3.

Miller GM, Madras BK (2002). Polymorphisms in the $3^{\prime}$ untranslated region of human and monkey dopamine transporter genes affect reporter gene expression. Mol Psychiatry 7: 44-55.

Ouellet-Morin I, Wigg KG, Feng Y, Dionne G, Robaey P, Brendgen $\mathrm{M}$ et al (2008). Association of the dopamine transporter gene and ADHD symptoms in a Canadian population-based sample of same-age twins. Am J Med Genet B Neuropsychiatr Genet 147B: $1442-1449$.

Papp A, Pinsonneault J, Cooke G, Sadee W (2003). Single nucleotide polymorphism genotyping using allele-specific PCR and fluorescence melting curves. Biotechniques 34: 1068-1072.

Pattarachotanant N, Sritharathikhun T, Suttirat S, Tencomnao T (2010). Association of $\mathrm{C} / \mathrm{T}$ polymorphism in intron 14 of the dopamine transporter gene (rs40184) with major depression in a northeastern Thai population. Genet Mol Res 9: 565-572.

Pinsonneault J, Nielsen C, Sadee W (2004). Genetic variants of the human $\mathrm{H}+$ /dipeptide transporter PEPT2: analysis of haplotype functions. J Pharmacol Exp Ther 311: 1088-1096.

Preuss UW, Zill P, Koller G, Bondy B, Sokya M (2007). D2 dopamine receptor gene haplotypes and their influence on alcohol and tobacco consumption magnitude in alcoholdependent individuals. Alcohol Alcohol 42: 258-266. 
Reese J, Kraschewski A, Anghelescu I, Winterer G, Schmidt LG, Gallinat J et al (2010). Haplotypes of dopamine and serotonin transporter genes are associated with antisocial personality disorder in alcoholics. Psychiatr Genet 20: 140-152.

Rehmsmeier M, Steffen P, Hochsmann M, Giegerich R (2004). Fast and effective prediction of microRNA/target duplexes. RNA 10: 1507-1517.

Saiz PA, Garcia-Portilla MP, Arango C, Morales B, Arias B, Corcoran $\mathrm{P}$ et al (2010). Genetic polymorphisms in the dopamine-2 receptor (DRD2), dopamine-3 receptor (DRD3), and dopamine transporter (SLC6A3) genes in schizophrenia: Data from an association study. Prog Neuropsychopharmacol Biol Psychiatry 34: 26-31.

Segman RH, Cooper-Kazaz R, Macciardi F, Goltser T, Halfon Y, Dobroborski $\mathrm{T}$ et al (2002). Association between the dopamine transporter gene and posttraumatic stress disorder. $\mathrm{Mol}$ Psychiatry 7: 903-907.

Smith RM, Alachkar H, Papp AC, Wang D, Mash DC, Wang J-C et al (2010). Nicotinic $\alpha 5$ receptor subunit mRNA expression is associated with distant $5^{\prime}$ upstream polymorphisms. Eur J Hum Genet 19: 76-83.

Talkowski ME, Kirov G, Bamne M, Georgieva L, Torres G, Mansour $\mathrm{H}$ et al (2008). A network of dopaminergic gene variations implicated as risk factors for schizophrenia. Hum Mol Genet 17: 747-758.
Todd RD, Jong YJ, Lobos EA, Reich W, Heath AC, Neuman RJ (2001). No association of the dopamine transporter gene $3^{\prime}$ VNTR polymorphism with ADHD subtypes in a population sample of twins. Am J Med Genet 105: 745-748.

VanNess SH, Owens MJ, Kilts CD (2005). The variable number of tandem repeats element in DAT1 regulates in vitro dopamine transporter density. BMC Genet 6: 55.

Wang D, Chen H, Momary K, Cavallari L, Johnson J, Sadée W (2008). Regulatory polymorphism in vitamin K epoxide reductase complex subunit 1 (VKORC1) affects gene expression and warfarin dose requirement. Blood 112: 1013-1021.

Wang D, Guo Y, Wrighton SA, Cooke GE, Sadee W (2010). Intronic polymorphism in CYP3A4 affects hepatic expression and response to statin drugs. Pharmacogenomics J. PMID 20386561 (in press).

Xu M, Xing Q, Li S, Zheng Y, Wu S, Gao R et al (2010). Pharacogenetic effects of dopamine transporter gene polymorphisms on response to chlorpromazine and clozapine and on extrapyramidal syndrome in schizophrenia. Prog Neuropsychopharmacol Biol Psychiatry 34: 1026-1032.

Zhang Y, Bertolino A, Fazio L, Blasi G, Rampino A, Romano R et al (2007). Polymorphisms in human dopamine D2 receptor gene affect gene expression, splicing, and neuronal activity during working memory. Proc Natl Acad Sci USA 104: 20552-20557.

Supplementary Information accompanies the paper on the Neuropsychopharmacology website (http://www.nature.com/npp) 